\title{
New human-computer interaction regulations for ship safe driving based on multi-mode data interconnection
}

\author{
Yi Yang ${ }^{1}$, Lixing Chen ${ }^{2}$, Pengfei $\mathrm{He}^{1}$, and Xingzhi $\mathrm{Lin}^{1, *}$ \\ ${ }^{1}$ Computer and Information Engineering College, Guangxi Vocational Normal University, Nanning \\ 530007, China \\ ${ }^{2}$ Business Administration College, Guangxi Vocational Normal University, Nanning 530007, China
}

\begin{abstract}
Based on the analysis of the multi-mode data of ship mechatronics and the new human-computer interaction regulations for safety driving, a new safety driving regulation based on multi-mode data is put forward. The new regulations for ship safe driving use mechanical and electrical data to form small-world data interconnection. Artificial intelligence and human-computer interaction operation information are used to integrate and communicate, and human-computer interaction data are incorporated to standardize driving behavior to integrate historical driving data, and finally, the standardized automatic self-driving is formed. The new human-computer interaction regulations formed by the safe driving system make it possible to solve and optimize the ship safe driving mode.
\end{abstract}

Keywords: Multi-mode data, Safe ship driving, Human-computer interaction, New regulations.

\section{Introduction}

The scale of ship navigation is expanding with the continuous development of the shipping industry, and water transportation is the most economical mode of transportation, but it also brings a series of safety issues. This highlights the necessity of establishing and standardizing new regulations for ship navigation in order to reduce the occurrence of navigation accidents. Specifically, the integrated driving behavior of human-computer interaction is constructed using ship equipment multi-mode data, detection and conversion technology, artificial intelligence application technology and driving mode, and thus, and combined with the data platform for data interconnection, intelligent analysis. Finally, the danger coefficient and the optimal navigation route are judged through optimization calculation and simulation, and the avoidance rules are generated automatically. In the design of human-computer interaction technology of ship safe driving multi-mode data, it is

\footnotetext{
*Corresponding author: 1xz4562509@,qq.com
} 
mainly supported by multi-mode data and human-computer interaction informatization to realize the standardization, automation and Informa ionization of ship safe driving. In this process, improves the safety performance and navigation quality of ship navigation, opens up new regulations for ship navigation, reflects the value of safe navigation and breaks the traditional navigation mode.

\section{Technical framework of the new human-computer interaction regulations for ship safe driving}

The ship safe driving human-computer interaction technology based on multi-mode data interconnection integrates multiple technologies, such as multi-mode data, detection and conversion, artificial intelligence application, to evaluate ship safe driving, and then control and intervene ships in a more reasonable manner. The multi-mode data interconnection technology establishes the ship big data platform through data collection during navigation, such as ship mechanical and electrical equipment, navigation environment, channel information, etc.. The data processing terminal intelligently analyzes the real-time information of ship navigation and forms a small local area network with a variety of ship data. The human-computer interaction procedure records the ship's driving habits through multi-mode data interconnection, processes and simulates the ship's route by the fusion of data and model, and then gives early warning and intervention to the ship. The new human-computer interaction regulation technology is composed of four layers: ship equipment layer, data layer, rule layer and application layer. The architecture diagram is shown in Fig. 1.

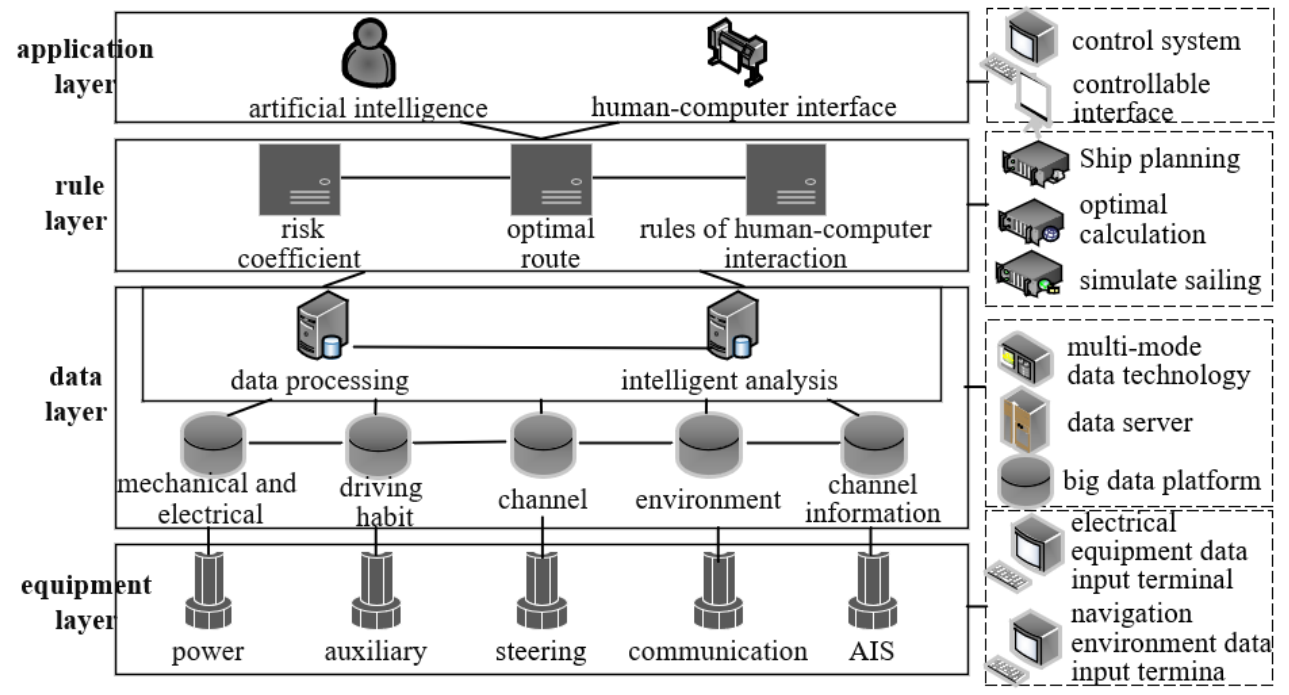

Fig. 1. Technical framework of new human-computer interaction regulations for ship safe driving.

First, the equipment layer. The ship equipment layer collects, retrieves and transmits the ship power equipment, auxiliary equipment, steering equipment, communication equipment and AIS information in real time through the ship mechanical and electrical equipment input terminal, navigation environment data input terminal and communication information input terminal.

Second, the data layer. The data layer mainly stores and processes multi-mode data, including mechanical and electrical equipment data, environmental data and channel information, channel data, driving habit data, etc., which is mainly completed by big data 
platform, multi-mode data interconnection technology. Realize the visualization and standardization of data server and ship information.

Third, the rule layer. The rule layer uses the data obtained from the data layer, calculates and simulates the ship navigation through the ship avoidance rules, obtains the ship risk coefficient, the optimal route and the rules of human-computer interaction, and establishes the ship safety early warning mode.

Fourth, the application layer. In the application layer, the fusion processing of ship multi-mode data and human-computer interaction rules is transformed into visual operation information, and the ship command is controlled through the human-computer interface to realize instruction input and output. For ship early warning and intervention, through interface display and voice broadcast, improve the safety and efficiency of navigation and promote the integrated development of safe driving environment.

\section{Standardized construction of ship safe driving human-computer interaction technology}

\subsection{Small world multi-mode data interconnection of ship mechatronics}

The ship is mainly composed of the hull, the ship power plant and the ship electrical. We first collect the mechanical and electrical data from the separate mechanical equipment, and deal with the block processing power plant, auxiliary equipment, steering device, communication equipment, AIS and so on in the equipment layer. The data are stored and input to the data processing terminal of the local area network. The data processing terminal interconnects with human-computer to intelligently analyze and process the data of mechanical and electrical equipment and sensors, iteratively optimize and feedback the ship data in real time, and construct the data environment ecosystem of ship electromechanical system.

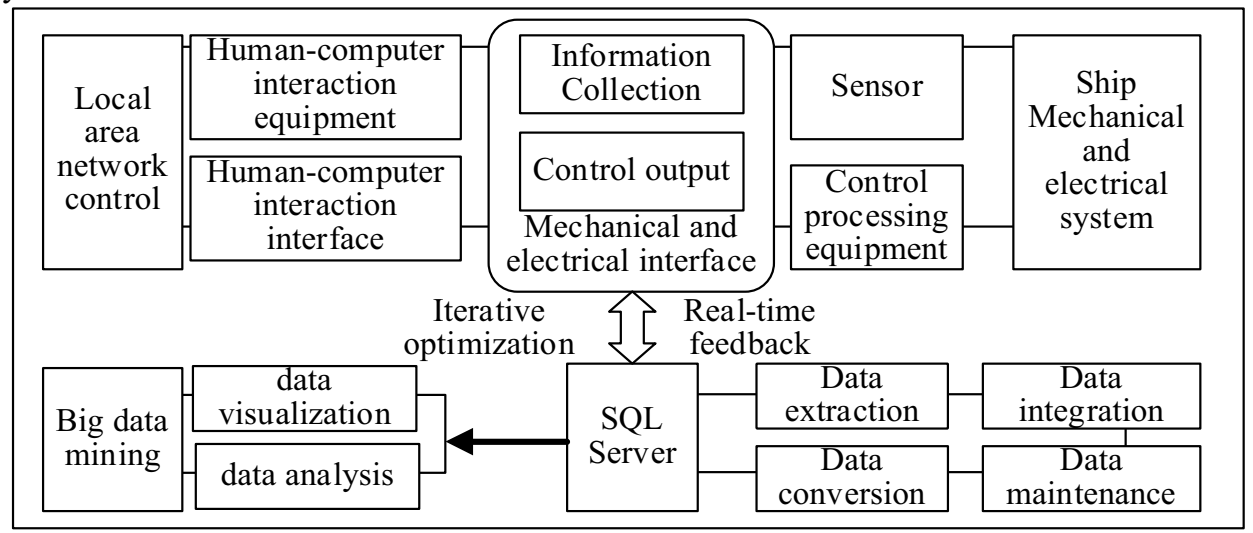

Fig. 2. Structural relationship of big data in the small world of ship mechatronics.

Ship mechatronics integrates electromechanical data acquisition, information processing and intelligent monitoring to form multi-mode data interconnection technology. The ship electromechanical system uses sensors, control processing devices and electromechanical interfaces to collect information and output control commands. The real-time feedback data are sent to the SQL Server database, and the database extracts, integrates, maintains and converts the data. The electromechanical data on board are monitored, controlled and maintained remotely. After data comparison, data analysis and model calculation, the results and data are transmitted to the ship to complete the data interconnection in ship 
navigation. Ship mechatronics small world big data consists of three parts: ship mechanical and electrical equipment, ship data acquisition and ship information processing, a data synthesis server, an information processing terminal and multiple data acquisition terminals constitute a local area network. The data integration server cooperates with the information processing terminal to simplify, standardize and visualize the information management of ship big data. Combined with database and information for iterative optimization and real-time feedback, a complete data and information exchange ecosystem is formed in the ship.

\subsection{Integrated safe driving system of artificial Intelligence and human-computer interaction}

The former relies on the ship big data platform for data mining, machine learning driving behavior information, intelligent algorithm to analyze and learn the ship navigation information, to find the optimal navigation route and environment, to warn the ship danger, to intervene the ship. Multi-mode data are uploaded to SQL Server database for preservation by artificial intelligence, and a small local area network is formed to facilitate the driver to extract and view. At the same time, strengthen the detection of the hidden dangers of the waterway and its own safety, manage the collected data, simplify the ship operating system, feedback the ship's driving information through the human-computer interface and the system, and realize the human-computer integrated communication.

Artificial intelligence plus the integration of human-computer interaction, artificial intelligence is introduced into human-computer interaction to realize self-learning, self-optimization and self-adaptation, and make full use of the data information of multi-mode data integration data platform. Realize the functions of intelligent prediction, independent planning, intelligent intervention and intelligent control to make ship navigation automatic and intelligent. When there are obstacles, reefs or dangerous ships in the ship's driving area, through ideal analysis and understanding, establish a mathematical model to choose the best driving route, intervene in the ship's danger early warning, use sensors to operate the ship to avoid, strengthen the ship's intervention, and broadcast and manipulate through the human-computer interaction page to reduce the collision accidents caused by the driver's negligence. The human-computer interactive control interface displays the menu bar, electronic chart, basic equipment, shipping suggestions, user information, ship operation console, and the pilot can monitor and control the ship directly from the screen.

Human-computer interaction is based on the interconnection of ship information-system-human information. In the case of self-driving, the multi-mode data is collected automatically, analyzed and sorted repeatedly in the control system, the human-computer interaction platform is constructed, and artificial intelligence is configured. The human-computer interaction system imitates the historical safe operation behavior of the ship, transforms the operation command, and achieves the function of human-computer interaction integrated operation and safe driving control.

\subsection{New regulations for human-computer interaction and automatic self-driving}

The new human-computer interaction regulations for ship safe driving based on multi-mode data interconnection adopts the interconnection of data information, simulates navigation according to the rules of human-computer interaction, and carries on the early warning intervention to the ship. The new human-computer interaction regulations for ship safe driving include multi-mode data integration regulations, ship early warning regulations and 
ship intervention regulations. Big data + artificial intelligence innovation combination, ship information real-time broadcast, warning to achieve accurate positioning of ship information, accurate warning.

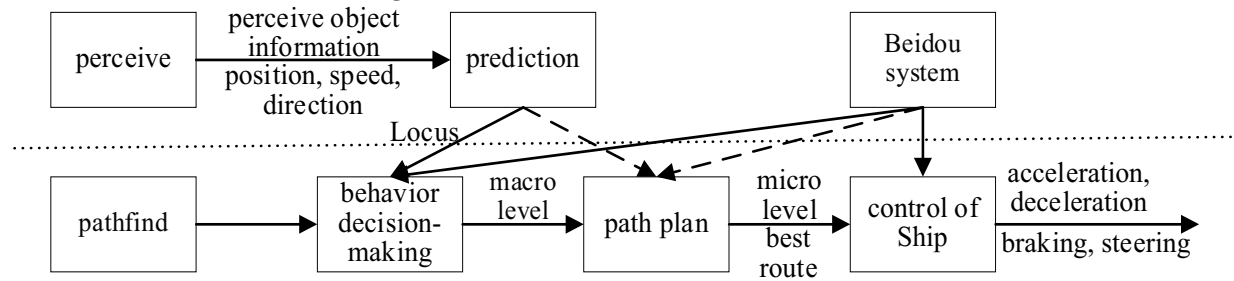

Fig. 3. Operation standardization module of human-computer interaction system in ship safe driving.

Figure 3 shows the operation standardization module of the ship safe driving human-computer interaction system. The perception module is responsible for obtaining the in-ship and out-of-ship data from the multi-mode mechatronics small world big data for monitoring, transmitting object information through the prediction module to establish a mathematical model, communicating information, establishing a ship management and control system, and generating a feasible locus. To meet the ship's own performance, waterway information constraints, the nature of obstacles to give specific speed and direction suggestions to the driver. Behavior decision-making and path planning can be intuitively understood as the ship's auxiliary navigation system, which is the result of routing, and directs the ship to travel and avoid at the macro level. The operation control module mainly controls the ship and forms safety measures by relying on artificial intelligence safe driving system identification. Ship decision-making mainly relies on Beidou system for real-time positioning, collecting channel information, predicting ship trajectory and ensuring ship safety.

Artificial intelligence + big data + electromechanical automation realizes the automatic operation of electromechanical equipment itself and promotes the automatic operation of driving safety control system. On the basis of automatic intervention of artificial intelligence, according to the technical performance and conditions of the new human-computer interaction regulations for ship safe driving, the self-driving design and optimize navigation data under the condition of ensuring the safety of ships.

It has the ability to automatically judge that the ship is a direct ship or give way ship, if the ship is a direct ship, then carry out simple automatic self-driving, the general system will not automatically take measures. If the risk of collision between the two ships reaches the highest, emergency collision avoidance measures will be carried out automatically. If the ship is a giving way ship, the advanced automatic self-driving will be carried out, and the system will take automatic evasion measures, and the relative orientation and course of the ship will remain unchanged until the giving way ship is cleared.

\section{Application and verification of new human-computer interaction regulations for ship safe driving}

\subsection{Application of new human-computer interaction regulations for ship safe driving}

The real-time data monitoring of the conventional ship safe driving system is used to provide data support for the rational application of the new human-computer interaction regulations. Through the Beidou positioning to analyze the navigation parameters and display the monitoring results, and the navigation route of the two ships is monitored 
calculating the position of the two ships. D, R, L is the linear distance between the ship and the obstacle, and $\theta$ represents the angle between the ship and the ship. So there is:

$$
\mathrm{R}=\mathrm{D} \csc \theta=\mathrm{Lsec} \theta
$$

Suppose that the coordinate of ship $A$ is $\left(x_{0}, y_{0}\right)$, the speed is $\mathrm{V}_{0}$, the heading is $\theta_{0}$, and the coordinate of ship $\mathrm{B}\left(x_{1}, y_{1}\right)$, the speed is $\mathrm{V}_{1}$, and the heading is $\theta_{1}$. The coordinate of ship An is the coordinate of ship A, and the velocity of ship An is (xonomy 0 ). The relative velocities of the two ships are on the $\mathrm{X}$ axis, the components of the $\mathrm{Y}$ axis and the relative speed are as follows:

$$
\begin{gathered}
\left\{\begin{array}{c}
V_{R x}=V_{1} \sin \theta_{1}-V_{0} \sin \theta_{0} \\
V_{R y}=V_{1} \cos \theta_{1}-V_{0} \cos \theta_{0}
\end{array}\right. \\
V_{R}=\sqrt{V_{R x}{ }^{2}+V_{R y}{ }^{2}}
\end{gathered}
$$

To ensure the safe navigation of the two ships, select and calculate the distance between the two ships and the relative speed direction between the two ships, real-time monitor the position of the two ships, timely early warning and human-computer interaction intervention. Among them, the value of $a_{0}$ depends on the relative speed of the two ships on the $\mathrm{X}$ axis $\mathrm{V}_{\mathrm{Rx}}$.

$$
\begin{array}{r}
\mathrm{R}_{1}=\sqrt{\left(\mathrm{x}_{1}-\mathrm{x}_{0}\right)^{2}+\left(\mathrm{y}_{1}-\mathrm{y}_{0}\right)^{2}} \\
\theta_{\mathrm{R}}=\mathrm{a}_{0}-\tan ^{-1} \frac{\mathrm{V}_{\mathrm{Ry}}}{\mathrm{V}_{\mathrm{Rx}}} \quad \mathrm{a}_{0}=\left\{\begin{array}{c}
90\left(\mathrm{~V}_{\mathrm{Rx}} \geq 0\right) \\
270\left(\mathrm{~V}_{\mathrm{Rx}} \leq 0\right)
\end{array}\right.
\end{array}
$$

The risk of ship collision directly affects the decision-making of (ship safe driving) human-computer interaction in safe navigation of ships. DCPA (the distance between ship and obstacle), TCPA (time to the closest point) and DCPA (the distance between ship and obstacle) are selected as the indexes to construct the risk function of ship collision. The feasibility of ship-computer interaction is verified by real-time monitoring of human-computer interaction ship risk by calculating DCPA and TCPA, during ship operation.

$$
\begin{aligned}
\text { DCPA } & =R_{1} \times \sin \left(\theta_{R}-\theta_{1}-\pi\right) \\
\text { TCPA } & =R_{1} \times \frac{\cos \left(\theta_{R}-\theta_{1}-\pi\right)}{V_{R}}
\end{aligned}
$$

\subsection{Data verification of new human-computer interaction regulations}

The work was supported by the project "Research on development and demonstration application of inland river green high-tech cargo ship" from Guangxi Innovation-driven Development Special Fund Project under Grant No. AA18118033, High Level Innovation Team and Outstanding Scholar Program of Guangxi Colleges and Universities under Grant (2019) No. 52-6 and the project "Research on ship's safe driving control system" from Guangxi Undergraduate Innovation and Entrepreneurship Training Program under Grant No.202014684001. 
Table 1. The unmanned navigation regulations.

\begin{tabular}{|c|c|c|c|}
\hline Rules & $\boldsymbol{\theta}_{\mathrm{R}}$ & Two-ship relationship & behavior decision-making \\
\hline 1 & {$\left[350^{\circ}, 360^{\circ}\right)$} & Crossover encounter & $\begin{array}{l}\text { Ship A does not take action and takes } \\
\text { appropriate avoidance measures if the } \\
\text { danger of collision reaches an imminent } \\
\text { situation }\end{array}$ \\
\hline 2 & {$\left[0^{\circ}, 10^{\circ}\right)$} & Crossover encounter & Turn right \\
\hline 3 & {$\left[10^{\circ}, 70^{\circ}\right)$} & $\begin{array}{l}\text { Crossing encounter on } \\
\text { starboard side at a small } \\
\text { angle }\end{array}$ & Turn right \\
\hline 4 & {$\left[70^{\circ}, 130^{\circ}\right)$} & $\begin{array}{l}\text { Crossing encounter on } \\
\text { starboard side at a big } \\
\text { angle }\end{array}$ & Turn left \\
\hline 5 & {$\left[130^{\circ}, 260^{\circ}\right)$} & Chase over & $\begin{array}{l}\text { Ship A does not take action and takes } \\
\text { appropriate avoidance measures if the } \\
\text { danger of collision reaches an imminent } \\
\text { situation }\end{array}$ \\
\hline 6 & {$\left[260^{\circ}, 350^{\circ}\right)$} & Crossing on port side & $\begin{array}{l}\text { Ship A does not take action and takes } \\
\text { appropriate avoidance measures if the } \\
\text { danger of collision reaches an imminent } \\
\text { situation }\end{array}$ \\
\hline
\end{tabular}

When the ship data is collected to the danger of the ship route, the monitoring distance and angle will be used to warn the ship, and when it reaches a certain limit, it will be connected to the ship automatic control system, interfere with the ship.

Table 2. The distance between the bow and the obstacle when generating early warning.

\begin{tabular}{c|cccccc} 
Deflection & $0^{\circ}$ & $15^{\circ}$ & $30^{\circ}$ & $45^{\circ}$ & $60^{\circ}$ & $75^{\circ}$ \\
\hline speed & & & & & & \\
\hline $8 \mathrm{kn}$ & $877 \mathrm{~m}$ & $620 \mathrm{~m}$ & $550 \mathrm{~m}$ & $510 \mathrm{~m}$ & $491 \mathrm{~m}$ & $488 \mathrm{~m}$ \\
$13 \mathrm{kn}$ & $1560 \mathrm{~m}$ & $1254 \mathrm{~m}$ & $1153 \mathrm{~m}$ & $1032 \mathrm{~m}$ & $998 \mathrm{~m}$ & $980 \mathrm{~m}$ \\
$18 \mathrm{kn}$ & $2453 \mathrm{~m}$ & $2036 \mathrm{~m}$ & $1950 \mathrm{~m}$ & $1880 \mathrm{~m}$ & $1560 \mathrm{~m}$ & $1480 \mathrm{~m}$ \\
$22 \mathrm{kn}$ & $3350 \mathrm{~m}$ & $2950 \mathrm{~m}$ & $2648 \mathrm{~m}$ & $2460 \mathrm{~m}$ & $2065 \mathrm{~m}$ & $1930 \mathrm{~m}$
\end{tabular}

Table 3. The distance between the bow and the obstacle when generating the intervention.

\begin{tabular}{c|cccccc} 
Deflection & $0^{\circ}$ & $15^{\circ}$ & $30^{\circ}$ & $45^{\circ}$ & $60^{\circ}$ & $75^{\circ}$ \\
\hline speed & & & & & & \\
\hline $8 \mathrm{kn}$ & $300 \mathrm{~m}$ & $250 \mathrm{~m}$ & $230 \mathrm{~m}$ & $200 \mathrm{~m}$ & - & - \\
$13 \mathrm{kn}$ & $450 \mathrm{~m}$ & $410 \mathrm{~m}$ & $380 \mathrm{~m}$ & $320 \mathrm{~m}$ & $320 \mathrm{~m}$ & - \\
$18 \mathrm{kn}$ & $520 \mathrm{~m}$ & $460 \mathrm{~m}$ & $460 \mathrm{~m}$ & $430 \mathrm{~m}$ & $430 \mathrm{~m}$ & $430 \mathrm{~m}$ \\
$22 \mathrm{kn}$ & $605 \mathrm{~m}$ & $570 \mathrm{~m}$ & $550 \mathrm{~m}$ & $550 \mathrm{~m}$ & $550 \mathrm{~m}$ & $550 \mathrm{~m}$
\end{tabular}

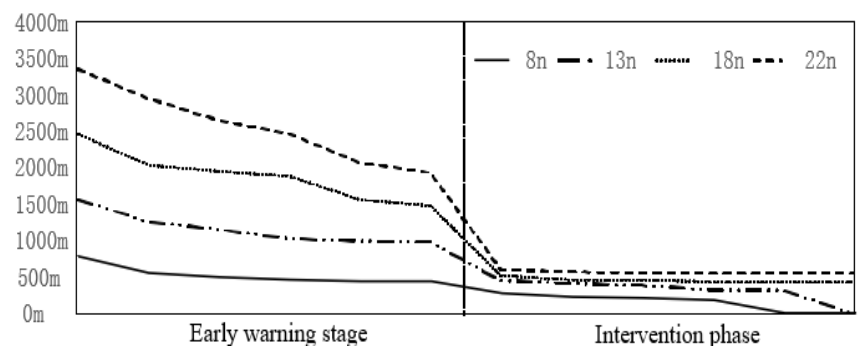

Fig. 4. Ship human-computer interactive operation curve.

By calculating the risk degree of the ship, the feasibility and stability of the ship human-computer interaction system are verified, and the ship human-computer interaction operation curve is obtained. First of all, collect the ship's own parameters such as heading, 
speed and weight, input them into the data synthesis server, and analyze the data of the unmanned navigation rules; secondly, generate early warning, intervention and unmanned navigation to the ship according to the unmanned navigation rules; finally, determine the position and driving risk of the ship, and verify the feasibility and stability of the human-computer interaction system.

\section{Conclusion}

With the multi-mode data of hull electromechanical data, historical driving data and navigation environment data, a new human-computer interaction regulation for ship safe driving based on multi-mode data interconnection is formed. The multi-mode data collects and records the ship's mechanical and electrical data, stores them on the Internet, judges whether the ship's equipment is faulty, interconnects with the human-computer, and records the driving data with multi-mode data. The system will judge the navigation environment according to the ship driving historical data and warn the dangerous environment in advance. Multi-mode data interconnection provides data verification for human-computer interaction and autopilot in a fixed channel, which promotes the development of a new mode in the shipbuilding industry.

The work was supported by project "Research on development and demonstration application of inland river green high-tech cargo ship" from Guangxi Innovation-driven Development Special Fund Project under Grant No. AA18118033, project "Research on control system of ship safe driving" from Guangxi High Level Innovation Team and Outstanding Scholar Program of University under Grant No. 2019-52-6 and "Research on Ship Safe Driving Control System" in Guangxi Undergraduate Innovation and Entrepreneurship Training Program Project under Grant No.202014684001.

\section{References}

1. Ning Wu, Huang Haizun, Lin Xingzhi. Monitoring and Application Optimization of Power Consumption Situation of the Solar Photovoltaic System Inland Ship [J]. Marine Electric, 2020, 40(10):9-13.

2. Liu Shulun. Research on Small Ship Anti-collision Algorithm Based on Millimeter Wave [J]. Journal of Guangzhou Maritime College, 2020, 28(03):21-24.

3. Li Lanxiu. Application of automatic ship identification system in collision avoidance technology for inland rivers [J]. Ship Science and Technology,2020, 42(02):16-18.

4. Sun Shuhong, Wang Jian. The Application of $3 D$ Visual Simulation System for Marine Manufacture [J]. Software Industry and Engineering,2015(06):52-56+41.

5. Wang Qun, Zhang Qingnian, Yang Jie, Cong Zhe, Tu Min. Research on Navigation Behavior Decision Model of Unmanned Ship in Inland Waters [J]. Journal of Wuhan University of Technology,2021,45(01):44-48+53.

6. Zhang haitao, Ha jianlin. The Trend Of The Development Of Marine Automation [J]. China Water Transport,2006(05):10-11. 